\title{
Curiosity About People: The Development of a Social Curiosity Measure in Adults
}

\author{
Britta Renner \\ Jacobs Center for Lifelong Learning and Institutional Development \\ International University Bremen
}

\begin{abstract}
Curiosity refers to the desire for acquiring new information. The aim of this study was to develop a questionnaire to assess social curiosity, that is, interest in how other people think, feel, and behave. The questionnaire was administered to 312 participants. Factor analyses of the 10item Social Curiosity Scale (SCS) yielded 2 factors: General Social Curiosity and Covert Social Curiosity. Evidence of convergent validity was provided by moderately high correlations of the SCS with other measures of curiosity and self-perceived curiosity, whereas discriminant validity was demonstrated by low correlations of the SCS with other personality traits, such as neuroticism and agreeableness. Of interest, social interaction anxiety was observed to facilitate covert social curiosity while inhibiting general social curiosity.
\end{abstract}

Curiosity has been conceptualized as desire for new information and knowledge (e.g., Berlyne, 1954; Kashdan, Rose, \& Fincham, 2004; Litman \& Jimerson, 2004; Loewenstein, 1994). Given the importance of curiosity for learning and development (Berg \& Sternberg, 1985; Trudewind, 2000; Trudewind, Mackowiak, \& Schneider, 1999), personality theorists developed various measures to assess individual differences in curiosity. Most current measures for trait curiosity explore the desire to gain knowledge or sensory experience (e.g., interest in intellectual conundrums or interest in new sights and sounds), but these instruments do not measure social curiosity, defined as an interest in how other people behave, think, and feel. However, social curiosity is important for the building and use of social networks and relationships, which has been suggested as a central human task (Pickett, Gardner, \& Knowles, 2004). Therefore, the aim of the study presented here was to develop a new scale to measure individual differences in social curiosity.

\section{FACETS OF CURIOSITY}

It has long been the tradition to distinguish among various facets of curiosity rather than viewing it as a monolithic construct. For instance, Berlyne (1954) already drew a distinction between perceptual and epistemic curiosity. Building on this conception, interest in curiosity has recently gained momentum, as shown by the development of new scales to assess its various facets. For instance, perceptual curiosity re- fers to the acquisition of new information by sensory stimulation (e.g., sights, sounds, odors) and is assessed by the recently developed Perceptual Curiosity Scale (Collins, Litman, \& Spielberger, 2004). Another facet of curiosity refers to the tendency to seek out opportunities for acquiring facts, knowledge, and ideas, which is measured by the Epistemic Curiosity Inventory (Litman \& Spielberger, 2003). Of interest, the correlation of perceptual and epistemic curiosity is moderate, supporting the notion of distinct dimensions of curiosity (Byman, 2005; Collins et al., 2004; Litman \& Spielberger, 2003). Furthermore, other scales focus on the general capacity to experience curiosity (Melbourne Curiosity Inventory; Naylor, 1981), assess curiosity as a function of novelty and absorption (Curiosity and Exploration Inventory; Kashdan et al., 2004), or consider curiosity as a feeling of deprivation aroused by not having access to new information (Curiosity As a Feeling-ofDeprivation Scale; Litman \& Jimerson, 2004). In sum, the main focus of research has been to explore curiosity in the realms of perceptual experience and knowledge acquisition rather than curiosity regarding the social world.

\section{CURIOSITY IN THE SOCIAL WORLD}

To function efficiently in a changing and complex social environment, humans require information about those around them (Foster, 2004). Dunbar (2004) argued that gossip, in the broad sense of conversation about social and personal topics, 
is "the core of human social relationships, indeed of society itself" (p. 100). Similarly, Baumeister, Zhang, and Vohs (2004) suggested that the exchange of social information makes an essential contribution to cultural learning. Thus, interest in how other people behave, think, and feel appears to be a fundamental prerequisite of human relationships. The importance of social curiosity was shown by a study assessing the content of conversations in public settings (Dunbar, Marriott, \& Duncan, 1997), which found that for two thirds of the time, and for both genders, conversations were mainly about "social topics," concerning either persons present or third parties. In a similar vein, most researchers in the fields of social perception processes (e.g., Swann, Stephenson, \& Pittman, 1981) and evolutionary psychology (Dunbar, 2004) have assumed that individuals seek knowledge of the social world to satisfy a need for effective control over the environment.

Various measures have been developed in previous research to assess aspects of social curiosity, such as social exploration and interpersonal curiosity, and for social psychology the emphasis has been on contextual factors that promote social exploratory behaviors. For instance, Swann et al. (1981) showed that individuals who had recently been deprived of control demanded more diagnostic information about a person they were due to interview than individuals who had not been deprived of control. Similarly, Green and Campbell (2000) developed the six-item Social Exploration Index to assess how likely people are to join new social circles ("I would enjoy being introduced to new people") or to disclose personal information ("I would like to strike up a conversation with a stranger on a bus or an airplane and open up to the person."). Although these measures appear to assess different aspects of exploratory behavior as statelike or traitlike individual differences, they do not measure the intensity of the motive that elicits them.

In the field of daydreaming style and imaginal processes, Singer and Antrobus (1972) developed the 12-item Interpersonal Curiosity scale as part of the Imaginal Process Inventory for assessing individual differences in people's interest in others. However, reviewing the item content suggests that the items assess aspects of interest in social information that are related to daydreaming (e.g., "I often notice a person at a restaurant or bar and wonder what he does for a living or what kind of person he is.") and an interest in the private lives of others ("I am not interested in the personal lives of prominent persons.") rather than a general interest in gaining new social information motivating exploratory behaviors. Consistent with this notion, Litman and Pezzo (2005) found that a shortened form of the Interpersonal Curiosity scale correlated positively and substantially with attitudes and selfevaluation for the transmission of gossip.

Current research instruments in perceptual and epistemic curiosity emphasize the need for new stimuli or information. In the same vein, social curiosity may be defined as an interest in gaining new information and knowledge about the social world. From this perspective, there is a lack of instruments for assessing individual differences in social curiosity. The possibility that various strategies might serve to satisfy social curiosity must also be considered. For instance, people may attempt to satisfy their social-related curiosity by taking active steps to acquire information about other persons, that is, asking them probing questions in the hope of unearthing hidden secrets. At other times, people might use less intrusive methods for acquiring social information about a person they are curious about, such as talking to their acquaintances or becoming especially attentive when others describe them (Swann et al., 1981). People might also use covert, even privacy-violating, strategies such as eavesdropping on conversations or observing people surreptitiously. The primary goals of this study were therefore to develop an instrument for measuring social curiosity that focused on the interest in acquiring new information and knowledge about the social world and determining how this motivates exploratory behaviors.

\section{CURIOSITY, ANXIETY, AND SOCIALIZATION}

Curiosity is often discussed in relation to anxiety, which may impact both the desire for acquiring new knowledge and exploratory strategies for satisfying curiosity. Curiosity and anxiety have often been conceptualized as opposing motivational systems, with the assumption that high levels of anxiety tend to inhibit curiosity (Kashdan, 2002; Kashdan \& Roberts, 2004a, 2004b; Spielberger \& Starr, 1994). In support of this notion, Litman and Spielberger (2003) found a small negative correlation between trait anxiety and epistemic curiosity. Other studies have reported similar findings regarding trait anxiety and measures of curiosity (Collins et al., 2004; Kashdan \& Roberts, 2004b; Litman \& Jimerson, 2004; Naylor, 1981). Furthermore, higher levels of state social anxiety were associated with lower levels of state curiosity (Kashdan \& Roberts, 2004a).

An alternative perspective assumes that anxiety impacts the strategies people use to satisfy their curiosity rather than the desire for new information or experiences (Trudewind, 2000; Trudewind et al., 1999). For instance, highly anxious children demonstrated overt exploratory behaviors, such as asking questions or manipulating new objects, less frequently compared to less anxious children (Lugt-Tappeser \& Schneider, 1987; Trudewind et al., 1999). However, highly anxious children did not differ from less anxious children with respect to their nonintrusive, observational behavior (e.g., perceptual inspection of a new box from a certain distance). Similarly, Kashdan (2004) found a significant negative correlation between social interaction anxiety and the Curiosity and Exploration Inventory, Exploration subscale, whereas the relationship with the Curiosity and Exploration Inventory, Absorption subscale was not significant. Accordingly, high socially anxious individuals might be as curious as low socially anxious individuals but show less social exploration. 
Interest in social information and social exploratory behaviors may also be modulated by social skills and competences (Buhrmester, Furman, Wittenberg, \& Reis, 1988; Mallinckrodt \& Wei, 2005). Whereas exploratory strategies such as asking questions are very effective in acquiring social information, a lack of social skills may prevent people from using such overt methods. Similarly, individuals with poor social relations, as indicated by low levels of social support and low levels of agreeableness, may be less motivated and may have fewer opportunities to acquire social information. Consistent with this notion, Green and Campbell (2000) found a substantial negative correlation between an avoidant attachment style and social exploration. Accordingly, interest in new social information and exploratory behaviors might be modulated by traits that either inhibit social interactions and socialization (e.g., neuroticism, social anxiety) or facilitate them (e.g., social competences, extraversion).

\section{THIS STUDY}

The aim of the study presented here was to develop a measure of social curiosity enabling the assessment of individual differences in the tendency to seek out novel social information. Furthermore, as information about the social world can be gained by various behavioral strategies, this study attempted to determine whether social curiosity is multifaceted and compartmented into distinct domains of interest. A further goal of the study was to determine the convergent and discriminant validity of this scale by examining its relationship with other measures of curiosity and other personality traits. In particular, it was predicted that social curiosity is a distinguishable aspect of curiosity. Finally, the study examined the relation of social curiosity and social anxiety. The perspective that social anxiety and social curiosity represent opposing motivational systems derives the hypothesis that both variables evince a significant negative correlation. Alternatively, based on the findings of Trudewind and colleagues (Trudewind, 2000; Trudewind et al., 1999), it is predicted that participants with higher social interaction anxiety are equally motivated and interested in new social information as participants lower in social interaction anxiety, but the former rely more on covert strategies to acquire social information.

\section{METHOD}

\section{Participants}

In total, 312 participants between the ages of 16 and 77 (66\% women) were recruited. There were 151 participants who came from introductory and upper level undergraduate university courses, and the mean age of this "younger" adult sample $(77 \%$ female) was 24 years $(S D=4.2)$. There were 160 participants who came from the community and were recruited through advertisements. The average age of this "older" adult sample ( $56 \%$ female) was 47 years $(S D=15.3)$. The older adult sample was on average 23 years older than the younger adult sample, $t(309)=17.32, p<.001, d=1.97$, and included a larger proportion of men, $\chi^{2}(1, N=3)=16.29$, $p<.001, r=.23, d$ equivalent $=.47$.

One participant had to be excluded from the data set because he failed to complete $97 \%$ of the questionnaire. Fiftythree participants $(17 \%)$ had $3 \%$ or less missing values. For these cases, missing items were imputed prior to forming scales by averaging the items that remained (cf. Schafer \& Graham, 2002).

\section{Instruments}

Each participant received a questionnaire including 12 scales. In responding to each scale, the participants were instructed to report how they "generally perceive themselves" on a 4-point scale ranging from 1 (strongly disagree) to 4 (strongly agree). Approximately 35 to $45 \mathrm{~min}$ were required to fill in the questionnaire.

The Epistemic Curiosity Inventory and the Curiosity and Exploration Inventory were translated into German in this study by three bilingual and bicultural individuals and me using the parallel blind technique (Behling \& Law, 2000). Analyses indicated that internal consistencies of the German and English versions were comparable, and exploratory factor analyses replicated the factorial structures of these scales.

EC. The Epistemic Curiosity Inventory (EC; Litman \& Spielberger, 2003) consists of 10 items asking about one's interest in exploring new ideas and figuring out how things work (e.g., "When I see a complicated piece of machinery, I like to ask someone how it works."). The newly translated German version of the EC scale exhibited good reliability in this study ( $\alpha=.84$, younger adult sample; $\alpha=.87$, older adult sample), which is comparable to previous research using the English version of the EC scale that ranged between $\alpha=.81$ and $\alpha=.85$ (Litman \& Spielberger, 2003).

CEI. The seven-item trait version of the Curiosity and Exploration Inventory (CEI; Kashdan et al., 2004) assesses two dimensions of trait curiosity: (a) exploration, which refers to appetitive strivings for novelty and challenge (e.g., "I would describe myself as someone who actively seeks as much information as I can in a new situation."), and (b) absorption, which refers to flowlike activity engagement ("When I am actively interested in something, it takes a great deal to interrupt me.”). The German CEI scale alpha coefficients were at an acceptable level for both the younger $(\alpha=$ $.69)$ and older $(\alpha=.72)$ adult samples and were comparable to the original English version, with alpha coefficients ranged from .72 to .80 (Kashdan et al., 2004).

$\mathrm{MCl}$. The Melbourne Curiosity Inventory-Trait Form (MCI; Naylor, 1981; German version: Saup, 1992) contains 
20 items that assess individual differences in the general capacity to experience curiosity (e.g., "I think learning 'about things' is interesting and exciting."). The internal consistency for the MCI was good, with alpha coefficients of .91 (younger adult sample) and .93 (older adult sample), which is comparable to previous studies that yielded alpha coefficients of between .90 and .93 in adult samples (Naylor, 1981; Saup, 1992).

SIAS. The Social Interaction Anxiety Scale (SIAS; Mattick \& Clarke, 1998; German version: Stangier, Heidenreich, Berardi, Golbs, \& Hoyer, 1999) is a 20-item measure assessing general fears and avoidance behaviors concerning social interactions (i.e., "I find myself worrying that I won't know what to say in social situations."). The internal consistency was good, with alpha coefficients of .92 (younger adult sample) and .91 (older adult sample), and was very similar to alpha coefficients reported in previous research, which ranged from .90 to .94 (Mattick \& Clarke, 1998; Stangier et al., 1999).

Social competence measures. Three different measures were chosen as indicators of social competence. The Social Competence (Soziale Kompetenz) subscale of the German version of the 16PF Fifth Edition (Schneewind \& Graf, 1998) consists of 12 items (e.g., "I consider myself to be sociable and self-confident in other people's company."). The internal consistency of the scale in this study was good (younger adult and older adult sample $\alpha=.92$ ). The Interpersonal and Social Skills (Kontakt- und Umgangsfähigkeit) subscale of the Frankfurter Self-Concept (FSC) Scale (Deusinger, 1986) includes 6 items assessing sociability and social interaction skills (e.g., "I have a good way of dealing with other people."). However, the internal consistency of the scale was comparably low $(\alpha=.61$, younger adult sample; $\alpha$ $=.58$, older adult sample). The Perceived Available Social Support subscale of the Berliner Social Support Scales (BSSS; Schulz \& Schwarzer, 2003) consists of 8 items assessing whether people believe that other people are willing to support them either emotionally or instrumentally when necessary (e.g., "I know some people on whom I can always rely."). Reliability was good ( $\alpha=.91$, younger adult sample; $\alpha=.86$, older adult sample), replicating previous results reported by Schulz and Schwarzer.

Personality traits. Neuroticism, Extraversion, and Agreeableness were assessed using the 12-item scales from the German version of the NEO-Five Factor Inventory (NEO-FFI; Borkenau \& Ostendorf, 1993). Coefficient alphas for the three traits obtained in the current study were as follows: Neuroticism $(\alpha=.87$ and .86 for both the younger and older adult sample, respectively), Extraversion $(\alpha=.81$ for the younger and older adult sample), and Agreeableness $(\alpha=.78$ and .77 for the younger and older adult sample, respectively). All alphas were comparable to those reported by
Borkenau and Ostendorf (1993; Neuroticism $\alpha=.85$, Extraversion $\alpha=.80$, and Agreeableness $\alpha=.71$ ) except for the Agreeableness scale, which yielded somewhat higher alphas in this study.

Self-ratings of curiosity and personality traits. Selfratings are often quite valid measures of trait constructs (Burisch, 1984). Therefore, participants were asked to rate themselves on the following six personality traits: curiosity, sociability, popularity, self-esteem, anxiety, and shyness. Answers were given on a 4-point scale ranging from 1 (definitely true) to 4 (definitely not true). Participants were also asked to judge themselves on the six personality traits compared to an average peer of the same sex. Answers were given on a 7-point comparative rating scale ranging from 1 (much below average) to 4 (average) to 7 (much above average). Of interest, participants rated themselves on average as being more curious than an average peer $(M=4.48, S D$ $=1.17), t(311)=7.21, p<.001, d=0.82$, suggesting that participants appraised curiosity as a rather desirable trait. No statistically significant differences emerged between the younger $(M=4.52, S D=1.21)$ and older adult samples $(M$ $=4.44, S D=1.14), t(309)<1$, in terms of self-rated comparative curiosity. Absolute and comparative ratings correlated highly for all six personality self-ratings $(r=.53$ to $.78, p<.001)$. For each personality trait, the absolute and comparative ratings were collapsed after $z$ transformation into a single sum score.

\section{RESULTS}

\section{The Development and Refinement of the SCS}

The Social Curiosity Scale (SCS) was developed in four successive steps. First, an initial pool of 45 items was developed by experts and graduate students to assess a broad interest in the acquisition of new information about how other people behave, think, and feel, which then motivates exploratory behaviors. The goal was to develop items that described a general interest in learning and acquiring new information about others and social exploratory behavior. Second, 15 obviously redundant or ambiguously worded items were deleted from this pool. Third, the remaining 30 items were examined by one independent expert, three psychology graduate students, and the author to determine whether they referred to an interest in acquiring new interpersonal information. To achieve a concise scale, any item that was not selected by all of the raters was removed from the pool. This resulted in a reduced set of 15 items, which as a fourth step were submitted to statistical analyses. Because previous research has shown age differences with respect to trait curiosity (Giambra, Camp, \& Grodsky, 1992) and related constructs such as openness to experience (Staudinger \& Kunzmann, 2005), statistical analyses were conducted separately for the younger and older adult samples. 
To identify the best items for measuring individual differences in social curiosity, SCS items having item-total correlations of at least .30 and average interitem correlations of .20 or higher were considered for retention (Comrey, 1988). Separate principal axis factor analyses were computed for the younger and older adult samples (Thompson, 2004) for the 14 social curiosity items that met the criteria for retention. The number of factors to extract was determined by three criteria: Cattell's scree test, the parallel analysis of the eigenvalues, and Velicer's minimum average partial (MAP) test (cf. O'Connor, 2000). The scree test showed a substantial drop in the eigenvalues after two factors for both samples. The parallel analysis of the eigenvalues also suggested the extraction of two factors. Specifically, within both samples, the first two eigenvalues from the respective actual data set (younger adult sample $=5.05,1.84,1.23, .90$; older adult sample $=5.27,2.14,1.07, .83$ ) were greater than the eigenvalues derived from the respective random data set (younger adult sample $=1.55,1.42,1.31,1.22$; older adult sample $=1.53,1.40,1.30,1.22)$. Furthermore, the MAP test also indicated the retention of two factors within both samples. A two-factor principle axis solution oblique (promax) rotation was therefore examined separately for the younger and older adult samples.

Factor loadings (pattern coefficients) of the 14 social curiosity items in the two-factor solution after oblique (promax) rotation are reported in Table 1. Factor 1 was defined by 7 items with dominant loadings of .47 or greater for both samples. Factor 2 comprised 5 items with dominant loading of .47 or greater for both samples. Two items (Items 13 and 14 in Table 1) had no clear dominant loading for the older or younger adult samples. The content of the items that defined Factor 1 described curiosity in other people's habits, feel- ings, and thinking (e.g., Item 1, "When I meet a new person, I am interested in learning more about him/her.") and is referred to as General Social Curiosity. The second factor, Covert Social Curiosity, included items such as eavesdropping on conversations or observing people surreptitiously (e.g., Item 9, "When on the train, I like listening to other people's conversations.").

The next step was to select items from the two social curiosity factors. To create a concise measure, the five best items of each factor were chosen to represent the corresponding factor. The five items with strong loadings on Factor 1 were selected to form the SCS-General (SCS-G) subscale, and the five items that defined Factor II formed the SCS-Covert (SCS-C) subscale. A principal axis factor analysis of the 10 SCS items yielded the two social curiosity factors with simple structure after oblique (promax) rotation (see Table 1). All SCS-G items had dominant loadings on the first factor for both groups, whereas the five SCS-C items all had dominant loadings on the second factor. No dual loadings of .21 or greater were found. An equal number of measured variables are correlated with each factor, whereby all measured variables are appreciably correlated with only one factor, which indicates a simple structure (cf. Thompson, 2004). The correlations between the two factors were .52 for the younger and .44 for the older adult sample. The two social curiosity subscales were combined to form a 10-item SCS.

To further secure the two-factorial structure of the SCS, confirmatory factor analyses (CFAs) using maximum likelihood solutions were conducted for both samples. The first CFA model tested the hypothesized two-factorial model with the two subscales SCS-G and SCS-C as correlated firstorder factors with paths leading to the 5 items hypothesized to comprise that factor (cf. Figure 1). The fit statistics of the

\section{Rotated (Promax) Factor Loadings (Pattern Coefficients) for the 14 Items and for the 10 Items Social Curiosity Scale}

\begin{tabular}{|c|c|c|c|c|c|c|c|c|c|}
\hline \multirow{3}{*}{$\begin{array}{l}\text { Item } \\
\text { No. }\end{array}$} & \multirow[b]{3}{*}{ Item Statement } & \multicolumn{4}{|c|}{14 Item Scale } & \multicolumn{4}{|c|}{10 Item Scale } \\
\hline & & \multicolumn{2}{|c|}{$S C S-G$} & \multicolumn{2}{|c|}{$S C S-C$} & \multicolumn{2}{|c|}{$S C S-G$} & \multicolumn{2}{|c|}{$S C S-C$} \\
\hline & & $O A$ & $Y A$ & $O A$ & $Y A$ & $O A$ & $Y A$ & $O A$ & $Y A$ \\
\hline 1 & When I meet a new person, I am interested in learning more about him/her. & .79 & .62 & -.10 & .12 & .79 & .63 & -.06 & .11 \\
\hline 2 & I'm interested in people. & .78 &.$\overline{75}$ & -.09 & -.11 & .75 & .75 & -.04 & -.11 \\
\hline 3 & I find it fascinating to get to know new people. & .76 & .63 & -.16 & -.11 & .74 & .63 & -.11 & -.13 \\
\hline 4 & I like to learn about the habits of others. & .68 & .59 & -.08 & .00 & .70 & .59 & .12 & .04 \\
\hline 5 & I like finding out how others "work." & .68 & .54 & .04 & .07 & .67 & .52 & .09 & .14 \\
\hline 6 & I'm interested in other people's thoughts and feelings. & .54 & .47 & .05 & -.09 & & & & \\
\hline 7 & Other people's life stories interest me. &.$\overline{47}$ &.$\overline{59}$ & .16 & .20 & & & & \\
\hline 8 & When other people are having a conversation, I like to find out what it's about. & .00 & .02 & .83 & .80 & .01 & .04 & .84 & .83 \\
\hline 9 & When on the train, I like listening to other people's conversations. & .01 & -.08 &.$\overline{78}$ &.$\overline{79}$ & .03 & -.02 &.$\overline{79}$ & .76 \\
\hline 10 & Every so often I like to stand at the window and watch what my neighbors are doing. & -.15 & -.17 & .73 & .74 & -.13 & -.16 & .71 & .73 \\
\hline 11 & I like to look into other people's lit windows. & -.04 & -.01 & .64 &.$\underline{.55}$ & -.05 & .02 & .63 & .48 \\
\hline 12 & When people quarrel, I like to know what's going on. & .22 & .23 & .58 & .47 & .17 & .20 & .59 & .48 \\
\hline 13 & When I see a crowd, I go over to see what's happening. & .36 & .16 & .26 & .34 & & & & \\
\hline 14 & I like to go to public places and watch the people going by. & .35 & .29 & .23 & .29 & & & & \\
\hline
\end{tabular}

Note. Pattern coefficients $>.40$ are underlined. SCS-G = Social Curiosity-General subscale; SCS-C = Social Curiosity-Covert subscale; OA = older adult sample $(n=160), \mathrm{YA}=$ younger adult sample $(n=151)$. 
two-factor model were compared to a more parsimonious structural model consisting of a single social curiosity factor with paths to all 10 items. In addition, both structural models were compared to a null model assuming that there are no factors present in the data (cf. Thompson, 2004). Structural equation models were run with AMOS 5 (Arbuckle, 2003) based on covariance matrices of the total sample and the two subsamples. The factor variance was fixed to 1.0, and the model fit was assessed by multiple goodness of fit indexes (GFIs) based on recommendations by Kline (1998) and by
$\mathrm{Hu}$ and Bentler (1999). The chi-squares and other GFIs for each model are reported in Table 2 for the two samples.

The chi-square statistics for the three models were significant within both samples $(p<.01)$. The difference between the chi-squares for these models indicated that the two-factor model had the smallest chi-square, provided a better fit than the one-factor model: younger adult sample, $\chi^{2}(1, N=5)=$ 92.34, $p<.001$, and older adult sample, $\chi^{2}(1, N=60)=$ $218.01, p<.001$. For both samples, the GFI, the comparative fit index (CFI), standardized root mean square residual

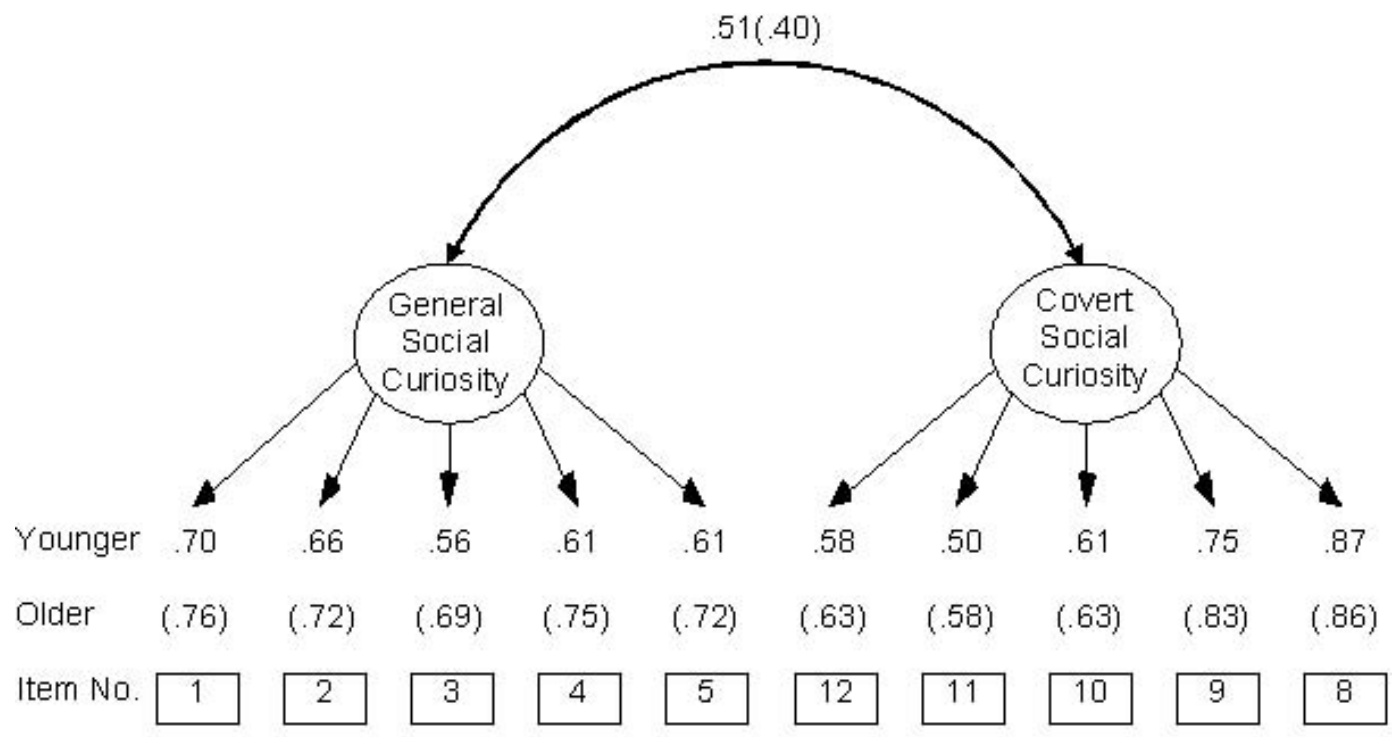

FIGURE 1 Standardized factor loadings and interfactor correlation for the two-factor social curiosity model for younger adults $(n=151)$ and older adults $(n=160$; in parentheses).

TABLE 2

Goodness-of-Fit Indicators for Models of SC for the Younger Adult and Older Adult Samples, and Models of Curiosity for the Total Sample

\begin{tabular}{|c|c|c|c|c|c|c|c|c|}
\hline Model and Sample & $\chi^{2}$ & $d f$ & $\Delta \chi^{2}$ & $G F I$ & $C F I$ & $S R M R$ & $R M S E A$ & $90 \% C I$ \\
\hline \multicolumn{9}{|l|}{ Younger adult sample } \\
\hline \multicolumn{9}{|l|}{ General and covert } \\
\hline \multicolumn{9}{|l|}{ Social curiosity } \\
\hline Null model & 480.86 & 45 & - & - & - & - & - & \\
\hline One-factor SC model & 163.05 & 35 & 317.81 & .78 & .71 & .12 & .16 & .13 to .18 \\
\hline Two-factor SC model & 70.71 & 34 & 92.34 & .91 & .92 & .07 & .08 & .05 to .10 \\
\hline \multicolumn{9}{|l|}{ Older Adult Sample ${ }^{\mathrm{b}}$} \\
\hline \multicolumn{9}{|l|}{ General and covert } \\
\hline \multicolumn{9}{|l|}{ Social curiosity } \\
\hline Null model & 686.78 & 45 & - & - & - & - & - & \\
\hline One-factor SC model & 284.77 & 35 & 402.01 & .65 & .61 & .16 & .21 & .19 to .24 \\
\hline Two-factor SC model & 66.76 & 34 & 218.01 & .92 & .95 & .06 & .07 & .05 to .09 \\
\hline \multicolumn{9}{|l|}{ Total sample } \\
\hline \multicolumn{9}{|l|}{ Social and trait curiosity } \\
\hline Null model & 736.21 & 15 & - & - & - & - & - & \\
\hline One-factor SC model & 81.88 & 9 & 654.33 & .92 & .90 & .09 & .16 & .13 to .19 \\
\hline Two-factor SC model & 33.69 & 7 & 48.19 & .97 & .96 & .05 & .10 & .06 to .13 \\
\hline
\end{tabular}

Note. $\quad N=311$. All $\chi^{2}$ and all $\Delta \chi^{2}$ are significant at $p<.001 . \mathrm{SC}=$ social curiosity; $\mathrm{GFI}=$ goodness-of-fit index; $\mathrm{CFI}=$ comparative fit index; $\mathrm{SRMR}=$ standardized root mean square residual; RMSEA = root mean square error of approximation; $\mathrm{CI}=$ confidence interval.

${ }^{\mathrm{a}} n=151 . \mathrm{b}^{\mathrm{b}}=160$. 
(SRMR) index, and the root mean square error of approximation (RMSEA) index were acceptable for the two-factorial model but not within the acceptable range for the onefactorial model. The standardized factor loadings for the two-factor social curiosity model are presented in Figure 1 separately for both samples. As expected, the standardized factor loadings were relatively high, ranging in magnitude from .50 to .87 . All factor loadings were significant indicating convergent validity $(p<.001)$. The interfactor correlation was moderate in size (younger adult sample, $r=.51$; older adult sample, $r=.40$ ), which suggests discriminant validity.

In a next step, it was tested whether the factor loadings of the SCS replicate across the two samples. Specifically, the initial two-group model in which no equality constraints were imposed was compared with a two-group model in which factorial loadings were constrained to be equal across both samples (cf. Thompson, 2004). The goodness of fit of the model for the two groups in combination and with no equality constraints imposed were satisfactory $(\mathrm{GFI}=.91, \mathrm{CFI}=.94, \mathrm{RMSEA}=$ $.05, \mathrm{SRMR}=.06), \chi^{2}(68, N=3)=137.47, p<.001$. The model with the factor loading constrained to be equal across groups yielded $\chi^{2}(76, N=3)=141.77, p<.001$. The two models did not differ significantly, $\chi^{2}(8, N=3)=4.29, n s$, indicating that the factor loadings related to the two-factorial social curiosity model were invariant. From the perspective of crossvalidation, this illustrated equality serves as support for the two-factor social curiosity model.

\section{Psychometric Properties of the Measures}

The means, standard deviations, and effect sizes (Pearson's $r$ ) for sample differences for all measures are reported in Table 3 separately for the younger adult and the older adult sample. A number of significant differences was observed between the younger and older adult samples. As Table 3 shows, the younger adult sample scored significantly higher than the older adult sample on the total SCS, on the SCS-G, and the SCS-C, $t \mathrm{~s}(309)>3.24, p<.01, r=-.18$ to -.24 . The younger adult sample also scored higher than the older adult sample on the Neuroticism scale, $t(309)=3.50, p<.001$, and the SIAS, $t(309)=4.48, p<.001, r=-.19$ and -.26 , respectively. Moreover, the younger adult sample reported a signifi-

TABLE 3

Means, Standard Deviations, Cronbach's Alpha Coefficients, and Effect Sizes for Sample Differences (Pearson's r) for Younger Adults and Older Adults

\begin{tabular}{|c|c|c|c|c|c|c|c|c|c|c|c|}
\hline & \multirow[b]{2}{*}{ Scale } & \multicolumn{3}{|c|}{ Total Sample } & \multicolumn{3}{|c|}{ Younger Adults ${ }^{\mathrm{b}}$} & \multicolumn{3}{|c|}{ Older Adults ${ }^{\mathrm{c}}$} & \multirow[b]{2}{*}{$r$} \\
\hline & & $M$ & $S D$ & $\alpha / r^{\mathrm{d}}$ & $M$ & $S D$ & $\alpha / r^{\mathrm{d}}$ & $M$ & $S D$ & $\alpha / r^{\mathrm{d}}$ & \\
\hline Social & SCS & 26.26 & 5.23 & .83 & 27.55 & 4.78 & .81 & 25.06 & 5.37 & .84 & $-.24 * * *$ \\
\hline \multirow[t]{2}{*}{ Curiosity } & SCS-G & 14.53 & 2.79 & .82 & 15.16 & 2.56 & .78 & 13.94 & 3.09 & .85 & $-.18 * *$ \\
\hline & SCS-C & 11.73 & 3.48 & .81 & 12.39 & 3.39 & .80 & 11.12 & 3.48 & .83 & $-.21 * * *$ \\
\hline Trait & MCI & 59.52 & 8.41 & .92 & 58.62 & 8.24 & .91 & 60.11 & 8.53 & .93 & .09 \\
\hline \multirow[t]{2}{*}{ Curiosity } & $\mathrm{EC}$ & 30.12 & 5.14 & .85 & 29.98 & 4.98 & .84 & 30.25 & 5.33 & .87 & .03 \\
\hline & CEI & 20.59 & 3.19 & .70 & 20.69 & 3.03 & .69 & 20.48 & 3.35 & .72 & -.03 \\
\hline Social & $16 \mathrm{PF}-\mathrm{C}$ & 31.81 & 7.97 & .93 & 29.74 & 7.72 & .92 & 33.67 & 7.64 & .92 & $.25^{* * *}$ \\
\hline \multirow[t]{2}{*}{ Competence } & FSC-C & 17.76 & 3.04 & .60 & 17.26 & 2.97 & .61 & 18.17 & 2.97 & .58 & $.15^{* *}$ \\
\hline & BSSS-A & 27.87 & 3.69 & .88 & 28.10 & 3.83 & .91 & 27.50 & 3.62 & .86 & -.08 \\
\hline Anxiety & SIAS & 37.22 & 10.9 & .92 & 40.34 & 11.2 & .92 & 34.58 & 9.82 & .91 & $-.26 * * *$ \\
\hline \multirow[t]{3}{*}{ NEO } & $\mathrm{N}$ & 25.01 & 6.90 & .87 & 26.45 & 6.72 & .87 & 23.83 & 6.71 & .86 & $-.19 * * *$ \\
\hline & $\mathrm{E}$ & 32.39 & 5.80 & .81 & 32.04 & 5.69 & .81 & 32.66 & 5.78 & .81 & .05 \\
\hline & A & 37.48 & 4.91 & .77 & 37.58 & 5.04 & .78 & 37.27 & 4.79 & .77 & -.03 \\
\hline \multirow[t]{2}{*}{ Curiosity $^{\mathrm{d}}$} & Absolute & 3.16 & 0.75 & & 3.24 & 0.70 & & 3.09 & 0.80 & & -.10 \\
\hline & Comp. & 4.48 & 1.17 & .64 & 4.52 & 1.21 & .67 & 4.44 & 1.14 & .62 & -.03 \\
\hline \multirow[t]{2}{*}{ Sociability $^{\mathrm{d}}$} & Absolute & 3.07 & 0.76 & & 3.01 & 0.76 & & 3.12 & 0.76 & & .07 \\
\hline & Comp. & 4.16 & 1.29 & .70 & 3.92 & 1.20 & .70 & 4.38 & 1.35 & .70 & $.18^{* *}$ \\
\hline \multirow[t]{2}{*}{ Popularity $^{\mathrm{d}}$} & Absolute & 2.91 & 0.55 & & 2.85 & 0.56 & & 2.96 & 0.53 & & .09 \\
\hline & Comp. & 4.30 & 0.91 & .57 & 4.21 & 0.89 & .58 & 4.39 & 0.91 & .54 & .10 \\
\hline \multirow[t]{2}{*}{ Self-Esteem ${ }^{\mathrm{d}}$} & Absolute & 2.89 & 0.71 & & 2.79 & 0.73 & & 2.98 & 0.67 & & $.13^{*}$ \\
\hline & Comp. & 4.35 & 1.21 & .72 & 4.16 & 1.25 & .78 & 4.53 & 1.43 & .63 & $.15^{* *}$ \\
\hline \multirow[t]{2}{*}{ Anxiety ${ }^{d}$} & Absolute & 2.01 & 0.85 & & 2.25 & 0.87 & & 1.78 & 0.78 & & $-.27 * * *$ \\
\hline & Comp. & 3.32 & 1.40 & .66 & 3.70 & 1.41 & .72 & 2.98 & 1.29 & .58 & $-.26 * * *$ \\
\hline \multirow[t]{2}{*}{ Shyness $^{\mathrm{d}}$} & Absolute & 2.17 & 0.92 & & 2.49 & 0.89 & & 1.87 & 0.86 & & $-.34 * * *$ \\
\hline & Comp. & 3.47 & 1.47 & .64 & 3.85 & 1.42 & .53 & 3.13 & 1.49 & .68 & $-.24 * * *$ \\
\hline
\end{tabular}

Note. $\quad$ SCS = Social Curiosity Scale; SCS-G = SCS-General subscale; SCS-C = SCS-Covert subscale; MCI = Melbourne Curiosity Inventory-Trait Form; EC $=$ Epistemic Curiosity Inventory; CEI = Curiosity and Exploration Inventory-Trait Form; $16 \mathrm{PF}-\mathrm{C}=16 \mathrm{PF}$ Social Competence subscale; FSC $-\mathrm{C}=$ Frankfurter Self-Concept Scale-Interpersonal and Social Skills subscale; BSSS-A = Berliner Social Support Scale-Perceived Available Social Support subscale; SIAS = Social Interaction Anxiety Scale; $\mathrm{N}=$ Neuroticism; E = Extraversion; A = Agreeableness; Absolute = absolute self-rating; Comp. = comparative self-rating. ${ }^{\mathrm{a}} n=311 . \mathrm{b}_{n}=151 .{ }^{\mathrm{c}} n=160^{\mathrm{d}}$ For self-ratings, correlation coefficients between absolute and comparative ratings are displayed. All correlations are significant at $p<$ .001 .

$* p<.05 . * * p<.01 . * * * p<.001$. 
cantly higher perceived anxiety and a higher perceived shyness than the older adult sample $(r=-.24$ to -.27$)$. On average, younger adults scored significantly lower for social competence measures than older adults on both the $16 \mathrm{PF}-$ Social Competence subscale, $t(309)=-4.51, p<.001$, and the FSC Interpersonal and Social Skills subscale, $t(309)$ $=-2.79, p<.001, r=.25$ and .15 , respectively. In accordance with these results, the younger adult sample also reported a significantly lower self-perceived self-esteem, and a lower perceived comparative sociability, than the older adult sample $(r=.13$ to .18$)$.

\section{Construct Validity of the SCS and Subscales}

To examine construct validity, correlations were computed between (a) the SCS and the SCS-G and SCS-C and (b) trait curiosity measures, personality measures, and perceived traits (see Table 4). Because separate analyses of the two samples yielded highly similar results, only data for the total sample are subsequently reported. (The results for the two subsamples are available on request from the author.)

Given the overlap of the items, the high correlations of the SCS with the SCS-G and SCS-C were expected. The moder-

TABLE 4

Correlations Between Social Curiosity Scales, Trait Curiosity Scales, and Other Personality Measures

\begin{tabular}{|c|c|c|c|}
\hline & $S C S$ & $S C S-G$ & $S C S-C$ \\
\hline \multicolumn{4}{|l|}{ Social Curiosity } \\
\hline SCS-G & $.80 * * *$ & & \\
\hline SCS-C & $.87 * * *$ & $.41 * * *$ & \\
\hline \multicolumn{4}{|l|}{ Trait Curiosity } \\
\hline $\mathrm{MCI}$ & $.39 * * *$ & $.52 * * *$ & $.16^{* *}$ \\
\hline $\mathrm{EC}$ & $.30 * * *$ & $.42 * * *$ & $.12 *$ \\
\hline CEI & $.31 * * *$ & $.44 * * *$ & $.12 *$ \\
\hline \multicolumn{4}{|l|}{ NEO } \\
\hline Neuroticism & .04 & -.09 & $.13^{*}$ \\
\hline Extraversion & $.37 * * *$ & $.40 * * *$ & $.23 * * *$ \\
\hline Agreeableness & .05 & .10 & -.01 \\
\hline \multicolumn{4}{|l|}{ Social Anxiety } \\
\hline SIAS & .04 & $-.15 * *$ & $.18 * *$ \\
\hline \multicolumn{4}{|l|}{ Social Competence } \\
\hline 16PF-Competence & $.12 *$ & $.26^{* * *}$ & -.03 \\
\hline FSC-Competence & $.15^{* *}$ & $.31 * * *$ & -.03 \\
\hline BSSS-Available Support & $.20 * * *$ & $.20 * * *$ & $.13^{*}$ \\
\hline \multicolumn{4}{|l|}{ Self-ratings } \\
\hline Curiosity & $.42 * * *$ & $.36^{* * *}$ & $.35 * * *$ \\
\hline Sociability & $.28 * * *$ & $.38 * * *$ & $.12 *$ \\
\hline Popularity & $.25 * * *$ & $.26^{* * *}$ & $.16^{* *}$ \\
\hline Self-esteem & .11 & $.22 * * *$ & -.01 \\
\hline Anxiety & .02 & -.09 & $.13^{*}$ \\
\hline Shyness & -.03 & -.11 & .06 \\
\hline
\end{tabular}

Note. $\quad N=311 . \mathrm{SCS}=$ Social Curiosity Scale; $\mathrm{SCS}-\mathrm{G}=\mathrm{SCS}-$ General; SCS-C = SCS-Covert; $\mathrm{MCI}=$ Melbourne Curiosity Inventory-Trait Form; $\mathrm{EC}=$ Epistemic Curiosity Inventory; CEI = Curiosity and Exploration Inventory-Trait Form; FSC $=$ Frankfurter Self-Concept Scale; BSSS = Berliner Social Support Scale; SIAS = Social Interaction Anxiety Scale; selfratings $=$ sum score of $z$-standardized absolute and comparative self-ratings. ${ }^{*} p<.05 .{ }^{* *} p<.01 . * * * p<.01$. ate correlation of .41 between the SCS-G and SCS-C is consistent with the assumption that these two subscales assess substantially related but meaningfully different components of an underlying social curiosity dimension.

The significant positive correlations of the SCS with the other three trait curiosity scales, ranging from $r=.30$ to .39 , provide evidence of convergent validity. However, these correlations are due primarily to correlations between the SCS-G and the trait curiosity measures. In particular, the correlations of the SCS-G with the MCI scale, the EC scale, and the CEI scale were all equal to or greater than .42. In contrast, comparably small albeit significant correlations were found between the SCS-C and the other curiosity measures, $r s \geq .12$. Of interest, a different pattern emerged for the selfrated curiosity score. The SCS and both subscales showed comparable positive correlations with self-rated curiosity, all $r \mathrm{~s} \geq .35$. Thus, the SCS-G and SCS-C seem to assess distinct components of social curiosity.

A significant positive correlation between the Extraversion scale, the SCS, and both subscales emerged, consistent with the notion that social curiosity and extraversion overlap to some extent, $r \mathrm{~s} \geq .23$. The correlations of the SCS and the SCS-G with Neuroticism and Agreeableness were essentially zero, which provides evidence of discriminant validity. Only the subscale SCS-C shows a significant positive correlation with Neuroticism $(r$ $=.13$ ), suggesting that negative affectivity is associated with some degree of covert social curiosity.

A similar pattern of results emerged for SIAS. SCS-C correlated positively with the social anxiety scale $(r=.18)$ and self-rated anxiety $(r=.13)$, suggesting that higher levels of social anxiety are associated with higher levels of covert social curiosity. Conversely, the subscale SCS-G correlated negatively with socially interaction anxiety $(r=-.15)$, indicating that social anxious participants tend to be less interested in acquiring new knowledge that is related to social and interpersonal topics.

Exploring the relation of social competence and social curiosity revealed that the correlations of the SCS, and particularly the SCS-G, with the three social competence scales were all higher than the corresponding correlations of the SCS-C with these measures. Specifically, the SCS-G correlated positively with the Social Competence subscale of the $16 \mathrm{PF}(r=.26)$, the Interpersonal and Social Skills subscale of the FSC $(r=.31)$, and the Perceived Available Social Support subscale of the BSSS $(r=.20)$. Similarly, positive correlations were found between self-rated sociability, self-rated popularity, and the SCS-G subscale $(r \geq .26)$. Thus, high general interest in social information was positively associated with a positive evaluation of one's own social abilities and skills, especially the initiating and enjoyment of social interactions, and the degree of perceived social support and integration. In contrast, the SCS-C subscale only correlated significantly with the Perceived Available Social Support subscale and with self-rated popularity $(r \geq .16)$. 


\section{Structural Relationship Between Social Curiosity and Trait Curiosity}

CFAs were conducted to examine the structural relationship between social curiosity, other trait curiosity measures, and self-perceived curiosity. The first CFA model to be tested consisted of a correlated two-factor structure composed of a Trait Curiosity factor measured by the three trait curiosity scales (MCI, EC, and CEI) and a Social Curiosity factor measured by the two social curiosity subscales (SCS-G, SCS-C). Considering the high correlations that were found between the self-rated curiosity and the social curiosity scales, an additional path from the self-rated curiosity to the Social Curiosity factor was included. Given the comparable high correlations that were found between the self-perceived curiosity and the trait curiosity scales (MCI, $r=.40 ; \mathrm{EC}, r=.38$; CEI, $r$ $=.37$; all $p s<.001$ ), a path from the self-perceived curiosity to the Trait Curiosity factor was also added. The second model consisted of a single curiosity factor with paths to each of the scales. Both structural models were compared to a null model.

As Table 2 shows, all three structural models yielded significant chi-squares (all $p s<.001$ ). However, the two-factor model was superior to the one-factor model, $\chi^{2}(2, N=3)=$ $48.19, p<.001$, whereas the one-factor model had a significantly better fit than the null model, $\chi^{2}(6, N=3)=654.33, p<$ .001. Only for the two-factor model were GFI and CFI greater than .90 and SRMR less than or equal to .08. However, the RMSEA was greater than .08. Therefore, the chisquare difference test and three out of four GFIs were most supportive of the two-factor model, providing further evidence that Trait Curiosity and Social Curiosity factors can be empirically differentiated.

The two factors were positively correlated $(r=.58)$, suggesting that Trait Curiosity and Social Curiosity reflected substantially related but distinct aspects of an underlying curiosity construct. Factor loadings for the standard model were as follows: (a) Trait Curiosity factor, MCI (.94), EC (.82), CEI (.73), and (b) Social Curiosity factor, SCS-G (.92) and SCS-C (.42). All factor loadings were significant $(p<$ $.05)$. However, self-reported curiosity shared a significant portion of variance with Trait Curiosity factor (.32) and Social Curiosity factor (.22). Additional analyses, comparing the initial two-group model in which no equality constraints were imposed with a two-group model in which factorial loadings were constrained to be equal across both samples, showed that the structure of the two-factorial curiosity model was invariant across the two samples, providing additional support for the two-factor curiosity model, $\chi^{2}(5, N=3)=$ 5.61, ns.

\section{Social Curiosity and Social Anxiety}

In a final step the relationship between the two different types of social curiosity (general vs. covert) and social anxiety was examined. In particular, it was tested whether high socially anxious individuals tend to acquire interpersonal information more frequently through covert behaviors while demonstrating a comparable general interest in interpersonal information as low socially anxious individuals (cf. Trudewind et al., 1999). Accordingly, an interaction between the type of social curiosity (general vs. covert) and social interaction anxiety (high vs. low) is expected.

High and low socially anxious individuals were selected using the SIAS, including the upper and lower quartile of the SIAS score distribution (cutoff scores SIAS $=53$ and $25 ; n=$ 77 , respectively). To determine the relationship between the two types of social curiosity with social interaction anxiety, repeated measures analyses of variance (ANOVAs) were conducted, with Type of Social Curiosity (general vs. covert) as within-subject factor (whereby the levels of this withinsubject factor are viewed as separate dependent variables) and Social Interaction Anxiety (low vs. high) as a betweensubjects factor. Results indicated a significant main effect, Type of Social Curiosity, $F(1,152)=91.57, p<.001, d=$ 1.55 , and a significant Type of Social Curiosity $\times$ Social Interaction Anxiety interaction, $F(1,152)=18.79, p<.001, d=$ .70. Simple main effects analyses were then conducted to decompose the interaction. As Figure 2 depicts, participants high in social interaction anxiety showed on average a significantly higher interest in covert interpersonal information acquisition than participants low in social interaction anxiety $(M=12.5, S D=3.5$ vs. $M=11.3, S D=3.7), F(1,152)=4.59$, $p<.05, d=.34$. Conversely, high socially anxious participants reported a significantly lower general interest in new interpersonal information than low socially anxious participants $(M=14.0, S D=2.9$ vs. $M=15.2, S D=3.1), F(1,152)=$ $5.83, p<.05, d=.40$.

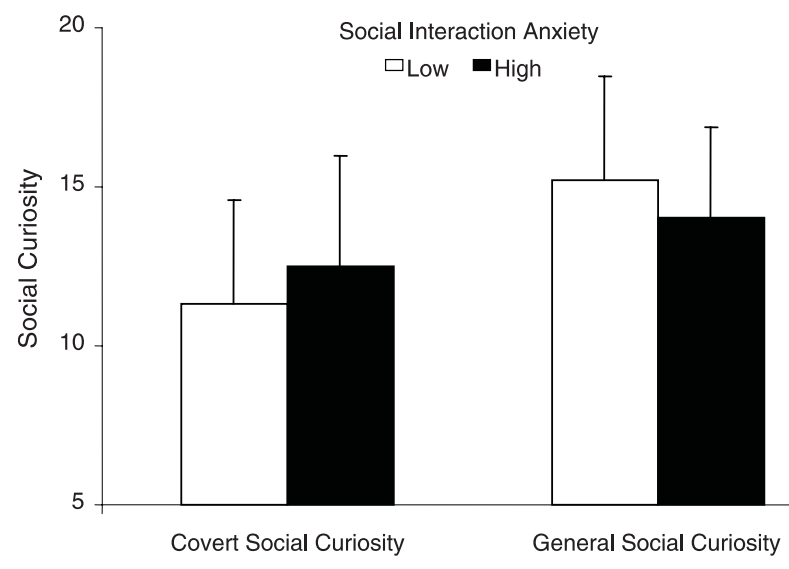

FIGURE 2 Mean covert and general social curiosity (and standard deviation) as a function of social interaction anxiety $(n=154)$. High and low social interaction anxiety was based on the 25th and 75th percentiles of the Social Interaction Anxiety scale, respectively. 


\section{DISCUSSION}

The main goal of the study presented here was to develop an assessment tool to measure individual differences in social curiosity as a personality trait. Principal axis factor analyses yielded two substantially correlated factors suggesting that social curiosity is a multifaceted construct. The General Social Curiosity factor describes a broad interest in the acquisition of new information about how other people behave, act and feel. A second factor entitled Covert Social Curiosity was composed of items expressing an interest in interpersonal information that is obtained primarily by unobtrusive or covert exploratory behaviors. Overall, this study provided a measure of social curiosity with an invariant two-factorial structure across the two samples, good psychometric properties, and the expected pattern of convergent and discriminant validity.

\section{Social Curiosity and Trait Curiosity}

Preliminary evidence of scale validity is encouraging. In particular, moderate positive correlations were found between the SCS and measures assessing curiosity in the realms of general knowledge and information acquisition (MCI, EC, and CEI). Furthermore, both social curiosity subscales and the three trait curiosity measures correlated significantly, and to a comparable degree with self-perceived curiosity. A willingness to label oneself as curious therefore appears to be substantially related to the different facets of curiosity. The pattern of results suggests considering social curiosity as a related but distinct aspect of curiosity.

It is of interest that the relationship of social curiosity to trait curiosity measures varied for the two subscales of the SCS. Assessing general interest in others, the SCS-G subscale revealed high positive correlations with other trait curiosity measures compared to the SCS-C subscale. Accordingly, it appears that the SCS-C in particular measures aspects of curiosity that are not assessed by other curiosity scales.

The study included a younger and older adult sample, and interesting differences with regard to social and trait curiosity were observed. Specifically, the younger adult sample reported higher scores on the social curiosity scales than the older adult sample, whereas no differences were found regarding epistemic and general curiosity. In contrast, Giambra et al. (1992) found that interpersonal and impersonal-mechanical curiosity was unabated by aging. These discriminant findings clearly need to be interpreted cautiously, as they may reflect differences in the applied measures and item content. Conceptualizing curiosity as a gap between existing knowledge and the anticipated information gain (Loewenstein, 1994), differences across the life span in social curiosity may reflect differences in social norm and area of knowledge and expertise. Overall, more research is needed to determine the generalizability of these findings to samples not represented in the study presented here.

\section{Social Curiosity and Social Anxiety}

A further interest of this study was to consider the relationship between social curiosity and social anxiety. Previous studies showed that high levels of social anxiety tend to inhibit trait curiosity (Kashdan, 2002; see also Mikulincer, 1997). Considering the SCS-G, the findings here appeared similar to the results observed for these trait curiosity measures. Specifically, the SCS-G showed negative correlations with the SIAS. However, analyzing the relationship between social curiosity and social anxiety with respect to the SCS-C suggested a somewhat different perspective. The negative correlation of social curiosity and social anxiety was specifically related to the subscale SCS-G, whereas the subscale SCS-C revealed a positive relationship with both the SIAS and Neuroticism. Additional ANOVAs revealed an interaction of social anxiety and social curiosity subscales, suggesting that in comparison to lower socially anxious individuals, higher socially anxious people report a higher level of interest in acquiring interpersonal information through covert exploratory behavior such as eavesdropping conversations. Conversely, an inverse pattern was found for the SCS-G subscale.

Taken together, depending on the type of analysis, existing theoretical conceptions on the relationship between social anxiety and social curiosity were also observed in this study. Considering the subscale SCS-G, a negative relationship with social anxiety emerged, consistent with the notion of opposing motivational systems of curiosity and anxiety (Kashdan \& Roberts, 2004a, 2004b; Spielberger \& Starr, 1994). However, focusing on the subscale SCS-C, results suggest that social anxiety modulates the means of satisfying social curiosity rather than generally inhibiting the motivation for social curiosity (Trudewind, 2000; Trudewind et al., 1999). More research is needed to delineate the differential relationships between social anxiety and the various facets of social curiosity.

\section{Social Curiosity and Social Functioning}

Considered from a broader theoretical perspective, social curiosity may reflect different motives for acquiring information about the social world. One important function of social curiosity may be a reflection of the need to live in a predictable and controllable social world (Swann et al., 1981). Socially anxious individuals might therefore depend more on covert curiosity because they are more in need of (re)gaining control of their environment. Furthermore, social curiosity might serve as a device for controlling social cheats and free riders, as Dunbar (2004) proposed in the realm of gossip (cf. also Litmann \& Pezzo, 2005). Another important function of social curiosity might be related to 
cultural learning (Baumeister et al., 2004) and the need to form a coherent map of the social environment (Foster, 2004). For instance, in many cases people perceive the exchange of gossip as providing useful information for their own lives (Baumeister et al., 2004). An interest in social and interpersonal information is therefore a central prerequisite for learning and development (Dunbar, 2004) and may serve interpersonal attachments and feelings of belonging (cf. Baumeister et al., 2004; Baumeister \& Leary, 1995). Thus, social curiosity might serve multiple motives related to social functioning.

Consistent with this notion, the findings presented here revealed positive correlations between the SCS and measures related to social functioning, such as extraversion and social competence. People who are interpersonally curious seem to be more likely to be socially competent, sociable, and able to build networks of relationships that provide support in the face of stressful life events. However, this study was not designed to specifically examine the relation of social curiosity and social functioning, and these results therefore need to be extended by future research. For instance, individual differences in responding to and processing new social and interpersonal information might influence interpersonal sensitivity (i.e., attention to and accuracy in decoding interpersonal social cues). Findings from research on interpersonal perception have already demonstrated that social experience facilitates the making and refining of social judgments (e.g., Funder, 1999; Vogt \& Colvin, 2003) and increases empathic accuracy over time (e.g., Marangoni, Garcia, Ickes, \& Teng, 1995). Thus, socially curious individuals might be proficient in adjusting their own behavior to successfully form new relationships and maintain existing ones (Kashdan \& Roberts, 2004a, 2004b).

\section{ACKNOWLEDGMENTS}

I thank Katja Haese, Freda-Marie Hartung, Fay Geisler, Felicitas Mander, Andries Oeberst, Anton Opholzer, Martina Panzer, Youlia Spivak, and Matthias Stamm for their assistance in conducting this study, and Tony Arthur, Almut Weike, and Ute Kunzmann for their critical reading of the manuscript. I am especially grateful to Harald Schupp for his valuable suggestions for this article.

\section{REFERENCES}

Arbuckle, J. L. (2003). Amos 5.0 user guide. Chicago: Small Waters. Baumeister, R. F., \& Leary, M. R. (1995). The need to belong: Desire for interpersonal attachments as a fundamental human motivation. Psychological Bulletin, 117, 497-529.

Baumeister, R. F., Zhang, L., \& Vohs, K. D. (2004). Gossip as cultural learning. Review of General Psychology, 8, 111-121.

Behling, O., \& Law, K. S. (2000). Translating questionnaires and other research instruments: Problems and solutions. Thousand Oaks, CA: Sage.
Berg, C. A., \& Sternberg, R. J. (1985). Response to novelty: Continuity versus discontinuity in the developmental course of intelligence. In H. Reese (Ed.), Advances in child development and behavior (Vol. 19, pp. 1-47). New York: Academic.

Berlyne, D. E. (1954). A theory of human curiosity. British Journal of Psychology, 45, 180-191.

Borkenau, P., \& Ostendorf, F. (1993). NEO-Fünf-Faktoren Inventar (NEO-FFI) [NEO-Five Factor Inventory]. Göttingen, Germany: Hogrefe.

Buhrmester, D., Furman, W., Wittenberg, M. T., \& Reis, H. T. (1988). Five domains of interpersonal competence in peer relationships. Journal of Personality and Social Psychology, 55, 991-1008.

Burisch, M. (1984). Approaches to personality inventory construction: A comparison of merits. American Psychologist, 39, 214-227.

Byman, R. (2005). Curiosity and sensation seeking: A conceptual and empirical examination. Personality and Individual Differences, 38, 1365-1379.

Collins, R. P., Litman, J. A., \& Spielberger, C. D. (2004). The measurement of perceptual curiosity. Personality and Individual Differences, 36, $1127-1141$

Comrey, A. L. (1988). Factor-analytic methods of scale development in personality and clinical psychology. Journal of Consulting and Clinical Psychology, 56, 754-761.

Deusinger, I. M. (1986). Frankfurter Selbstkonzeptskalen [Frankfurter SelfConcept scales]. Göttingen, Germany: Hogrefe.

Dunbar, R. I. M. (2004). Gossip in evolutionary perspective. General Review of Psychology, 8, 100-110.

Dunbar, R. I. M., Marriott, A., \& Duncan, N. D. C. (1997). Human conversational behavior. Human Nature, 6, 231-246.

Foster, E. K. (2004). Research on gossip: Taxonomy, methods, and future directions. Review of General Psychology, 8, 78-99.

Funder, D. C. (1999). Personality judgments: A realistic approach to person perception. San Diego, CA: Academic.

Giambra, L. M., Camp, C.J., \& Grodsky, A. (1992). Curiosity and stimulation seeking across the adult span: Cross-sectional and 6-8 year longitudinal findings. Psychology and Aging, 7, 150-157.

Green, J. D., \& Campbell, W. K. (2000). Attachment and exploration in adults: Chronic and contextual accessibility. Personality and Social Psychology Bulletin, 26, 452-461.

Hu, L. T., \& Bentler, P. M. (1999). Cutoff criteria for fit indexes in covariance structure analysis: Conventional criteria versus new alternatives. Structural Equation Modeling, 6, 1-55.

Kashdan, T. B. (2002). Social anxiety dimensions, neuroticism, and the contours of positive psychological functioning. Cognitive Therapy and Research, 26, 789-810.

Kashdan, T. B. (2004). The neglected relationship between social interaction anxiety and hedonic deficits: Differentiation from depressive symptoms. Journal of Anxiety Disorders, 18, 719-730.

Kashdan, T. B., \& Roberts, J. E. (2004a). Social anxiety's impact on affect, curiosity, and social self-efficacy during a high self-focus social threat situation. Cognitive Therapy and Research, 28, 119-141.

Kashdan, T. B., \& Roberts, J. E. (2004b). Trait and state curiosity in the genesis of intimacy: Differentiation from related constructs. Journal of Social and Clinical Psychology, 23, 792-816.

Kashdan, T. B., Rose, P., \& Fincham, F. D. (2004). Curiosity and exploration: Facilitating_positive subjective experiences and personal growth opportunities. Journal of Personality Assessment, 82, 291-215.

Kline, R. B. (1998). Principles and practice of structural equation modeling. New York: Guilford.

Litman, J. A., \& Jimerson, T. L. (2004). The measurement of curiosity as a feeling of deprivation. Journal of Personality Assessment, 82, 147-157.

Litman, J. A., \& Pezzo, M. V. (2005). Individual differences in attitudes towards gossip. Personality and Individual Differences, 38, 963-980.

Litman, J. A., \& Spielberger, C. D. (2003). Measuring epistemic curiosity and its diversive and specific components, Journal of Personality Assessment, 80, 75-86. 
Loewenstein, G. (1994). The psychology of curiosity: A review and reinterpretation, Psychological Bulletin, 116, 75-98.

Lugt-Tappeser, H., \& Schneider, K. (1987). Ängstlichkeit und das Erkunden eines neuen Objekts bei Vorschulkindern [Anxiety and exploration of a new object within preschoolers]. Zeitschrift für Entwicklungspsychologie und Pädagogische Psychologie, 19, 300-313.

Mallinckrodt, B., \& Wei, M. (2005). Attachment, social competencies, social support, and psychological distress. Journal of Counseling Psychology, 52, 358-367.

Marangoni, C., Garcia, S., Ickes, W., \& Teng, G. (1995). Empathic accuracy in a clinically relevant setting. Journal of Personality and Social Psychology, 68, 854-869.

Mattick, R. P., \& Clarke, J. C. (1998). Development and validation of measures of social phobia, scrutiny fear and social interaction anxiety. Behavior Research and Therapy, 36, 455-470.

Mikulincer, M. (1997). Adult attachment style and information processing: Individual differences in curiosity and cognitive closure. Journal of Personality and Social Psychology, 72, 1217-1230.

Naylor, F. D. (1981). A state-trait curiosity inventory. Australian Psychologist, 16, 172-183.

O'Connor, B. (2000). SPSS and SAS programs for determining the number of components using parallel analysis and Velicer's MAP test. Behavior Research Methods, Instruments, and Computers, 32, 396-402.

Pickett, C. L., Gardner, W. L., \& Knowles, M. (2004). Getting a cue: The need to belong and enhanced sensitivity to social cues. Personality and Social Psychology Bulletin, 30, 1095-1107.

Saup, W. (1992). Neugier und Interesse im (frühen) Alter [Curiosity and interest in later adulthood]. Zeitschrift für Gerontopsychologie und psychiatrie, 1, 1-10.

Schafer, J. L., \& Graham, J. W. (2002). Missing data: Our view of the state of the art. Psychological Methods, 7, 147-177.

Schneewind, K. A., \& Graf, J. (1998). Der 16-Persönlichkeits-Faktoren-Test, Revidierte Fassung (16 PF-R). Test manual. Bern, Germany: Huber.

Schulz, U., \& Schwarzer, R. (2003). Soziale Unterstützung bei der Krankheitsbewältigung. Die Berliner Social Support Skalen (BSSS) [Social support in coping with illness: The Berlin Social Support Scales (BSSS)]. Diagnostica, 49, 73-82.

Singer, J. L., \& Antrobus, J. S. (1972). Daydreaming, imaginal process and personality: A normative study. In P. W. Sheehan (Ed.), The function and nature of imagery (pp. 175-202). San Diego, CA: Academic.
Spielberger, C. D., \& Starr, L. M. (1994). Curiosity and exploratory behavior. In H. F. O'Neil, Jr., \& M. Drillings (Eds.), Motivation: Theory and research (pp. 221-243). Hillsdale, NJ: Lawrence Erlbaum Associates, Inc.

Stangier, U., Heidenreich, T., Berardi, A., Golbs, U., \& Hoyer, J. (1999). Die Erfassung sozialer Phobie durch die Social Interaction Anxiety Scale (SIAS) und die Social Phobia Scale (SPS) [Assessment of social phobia by the Social Interaction Anxiety Scale (SIAS) and the Social Phobia Scale (SPS)]. Zeitschrift für Klinische Psychologie, 28, 28-36.

Staudinger, U. M., \& Kunzmann, U. (2005). Positive adult development: Adjustment and/or growth? European Psychologist, 10, 320-329.

Swann, W. B., Stephenson, B., \& Pittman, T. S. (1981). Curiosity and control: On the determinants of the search for social knowledge. Journal of Personality and Social Psychology, 40, 635-642.

Thompson, B. (2004). Exploratory and confirmatory factor analysis. Washington, DC: American Psychological Association.

Trudewind, C. (2000). Curiosity and anxiety as motivational determinants of cognitive development. In J. Heckhausen (Ed.), Motivational psychology of human development: Developing motivation and motivating development (pp. 15-38). New York: Elsevier.

Trudewind, C., Mackowiak, K., \& Schneider, K. (1999). Neugier, Angst und kognitive Entwicklung [Curiosity, anxiety, and cognitive development]. In M. Jerusalem \& R. Pekrun (Eds.), Emotion, Motivation und Leistung (pp. 105-126). Göttingen, Germany: Hogrefe.

Vogt, D. S., \& Colvin, C. R. (2003). Interpersonal orientation and the accuracy of personality judgments. Journal of Personality, 71, 267-295. 